\title{
TEMPERATURE CONTROL SYSTEM WITH AC-AC CONVERTER BASED ON FUZZY LOGIC CONTROL
}

\author{
Abdul Muis Prasetia \\ Program Studi Teknik Elektro, Fakultas Teknik, Universitas Borneo Tarakan \\ prasetia.electric@gmail.com
}

\section{Dedy Harto}

Program Studi Teknik Elektro, Fakultas Teknik, Universitas Borneo Tarakan defariz@gmail.com

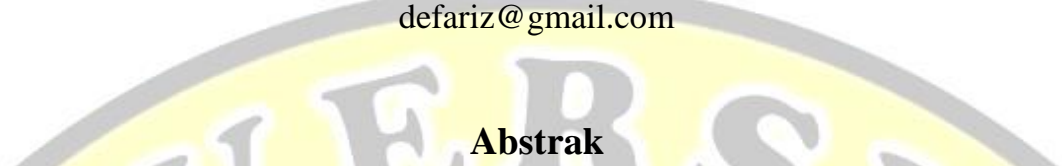

Makalah ini menyajikan sistem pengaturan suhu dengan konverter AC-AC melalui metode fuzzy logic control, penggunaan konverter AC-AC dilatarbelakangi oleh banyaknya aplikasi pengaturan suhu menggunakan pemanas listrik dan umumnya menggunakan prinsip on-off. Karena keterbatasan range pengaturan tegangan yang dapat diberikan, maka kontrol tegangan secara on-off kurang dapat memberikan akurasi nilai keluaran yang dibutuhkan sistem, sehingga untuk beberapa aplikasinya dapat menimbulkan tanggapan sistem pengaturan temperatur yang kurang baik. Untuk meningkatkan kinerja pengaturan suhu dengan memperluas range pengaturan tegangan digunakan konverter AC-AC. Pada penelitian ini usulkan pengaturan konverter dengan metode fuzzy logic kontrol. Hasil pengujian menunjukkan bahwa konverter dapat berfungsi dengan baik dan respon dapat mengikuti setpoint. Fuzzy logic control menunjukkan Rise time sebesar 3 menit, serta ketika telah mencapai setpoint yaitu $30^{\circ} \mathrm{C}$, suhu sedikit berosilasi dengan error steady state $0 \%$.

Kata Kunci: Suhu, Fuzzy logic control, Konverter AC-AC

\section{Abstract}

This paper presents temperature control system with AC-AC converter based on fuzzy logic control method, the selection of AC-AC converters is motivated by the many applications of temperature control system using electric heaters and generally using on-off principle. Due to the limited range voltage settings, then the on-off voltage control is less able to provide the accuracy of required output value of the system, so for some applications it can lead to bad temperature control system response. To improve the temperature performance by extending the range of voltage settings used AC-AC converter. In this research, propose the converter arrangement with fuzzy logic control method. The results show converter can function well and the response can follow setpoint. Fuzzy logic control shows 3 minutes rise time, when it reaches $30^{\circ} \mathrm{C}$ set point the temperature is slightly oscillated with $0 \%$ steady state error.

Keywords: Temperature, Fuzzy logic control, AC-AC converter.

\section{PENDAHULUAN}

Perkembangan teknologi yang semakin pesat telah membawa pengaruh yang sangat penting dalam dunia industri, salah satunya teknologi sistem kendali. Sangat dibutuhkannya sistem kendali yang baik untuk dapat menunjang jalannya proses industri yang lebih efisien dalam proses produksi. Pada dunia industri sistem termal memegang peranan yang sangat penting, misalnya untuk memproses suatu bahan atau zat harus dipanaskan terlebih dahulu hingga mencapai suhu tertentu (Puspita, 2016).

Namun sistem termal untuk memanaskan saja tidak cukup, tetapi sangat diperlukan sistem yang dapat menjaga besarnya suhu dalam proses agar tetap stabil pada nilai yang diinginkan. Untuk keperluan ini, maka harus digunakan suatu metode kontrol yang dapat meminimalkan nilai error pada sistem termal atau sistem pengaturan suhu.

Banyak diaplikasikan sistem pengaturan suhu menggunakan pemanas (heater) yang bersumber dari energi listrik. Pada umumnya untuk pengaturan tegangan pemanas digunakan prinsip pengaturan tegangan secara onoff. Namun karena keterbatasan range pengaturan tegangan yang dapat diberikan, maka kontrol tegangan secara on-off kurang dapat memberikan akurasi nilai keluaran yang dibutuhkan oleh sistem pengaturan, sehingga untuk beberapa aplikasinya dapat menimbulkan respon sistem pengaturan suhu yang berosilasi dan belum maksimal.

Rangkaian konverter Alternating Current to Alternating Current(AC-AC) merupakan rangkaian yang dapat menghasilkan tegangan keluaran $\mathrm{AC}$ variable dari sumber AC konstan. Untuk mendapatkan tegangan tersebut 
dapat menggunakan konverter AC-AC berupa inverter atau phase-angel control (PAC). Penggunaan tegangan AC variabel dapat memberikan akurasi nilai keluaran yang dibutuhkan oleh sistem pengaturan, dengan demikian dimungkinkan untuk memperoleh tanggapan sistem yang lebih baik (Sudjadi, 2005).

Konverter AC-AC akan berkerja dengan baik ketika dipasangkan dengan metode kontrol seperti PID, Fuzzy logic control, ANFIS dan lain-lain. Beberapa metode kontrol telah diterapkan pada rangkain power electronik seperti softstarter, konverter, inverter dan dapat berkerja sesuai dengan yang diinginkan. Akan tetapi metode fuzzy logic control memiliki keunggulan tersendiri, diantaranya mampu memodelkan fungsi-fungsi nonlinear yang sangat kompleks, memilki toleransi terhadap data-data yang tidak tepat, fleksibel, dan mampu mengaplikasikan pengalaman para pakar secara langsung tanpa harus melalui proses pelatihan (Maidah, 2012).

Berdasarkan uraian diatas pada makalah ini akan disampaikan penggunaa metode fuzzy logic control sebagai penentu besarnya tegangan pemanas berdasarkan sudut fasa pada sistem pengatur suhu melalui konverter AC-AC.

\section{METODE}

Ada beberapa proses yang dilakukan pada penelitian ini, diantaranya mendesain sistem pengaturan suhu, konverter AC-AC, zero crossing detector, sensor suhu, dan fuzzy logic control.

\section{Sistem Pengaturan Suhu}

Sistem pengaturan suhu sederhana dapat dilihat pada Gambar 1. Cairan dengan suhu $T\left({ }^{\circ} \mathrm{C}\right)$ mengalir keluar dari tangki dengan laju tertentu dan cairan ini digantikan dengan cairan yang masuk ke tangki dengan suhu $T i\left({ }^{\circ} \mathrm{C}\right)$, dimana $T i<T$. Cairan yang berada di dalam tangki dipanaskan menggunakan sebuah pemanas (heater) listrik. Mixer mengaduk cairan sedemikian rupa sehingga seluruh cairan yang berada dalam tangki dapat dianggap memiliki suhu yang sama.

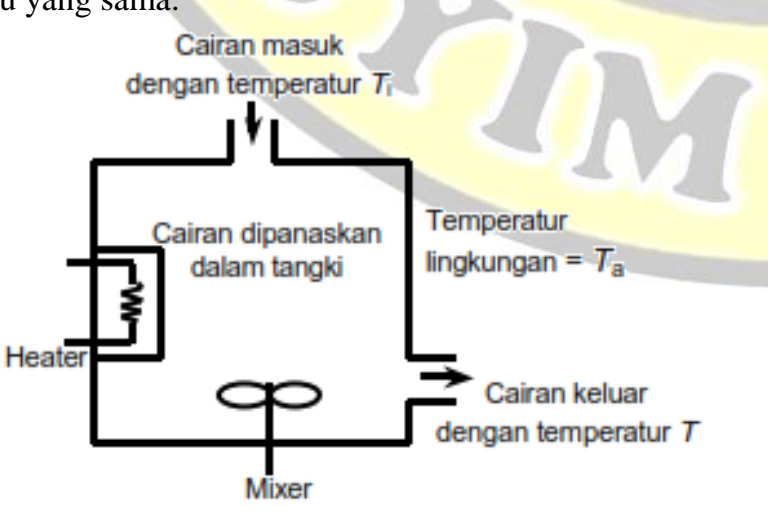

Gambar 1 Sistem Pengaturan Suhu

\section{Konverter AC-AC}

Tujuan utama dari konverter daya ini adalah mengubah tegangan AC menjadi tegangan AC yang vairiabel. Komponen utama yang digunakan dalam proses pensaklaran adalah bidirectional triode thyristor atau triac dengan prinsip kontrol sudut fasa dan zero crossing detector (Kitcharoenwat, 2013).

Sebagai komponen pengontrol tegangan digunakan triac BT138. Agar tidak membahayakan bagian pengontrol, maka digunakan IC MOC3021 untuk mengkopel triac dengan bagian pengontrolnya. Sinyal pemicuan dihasilkan dari sistem mikrokontroler. Gambar 2 merupakan rancangan rangkaian untuk pengontrol tegangan AC gelombang penuh satu fasa.

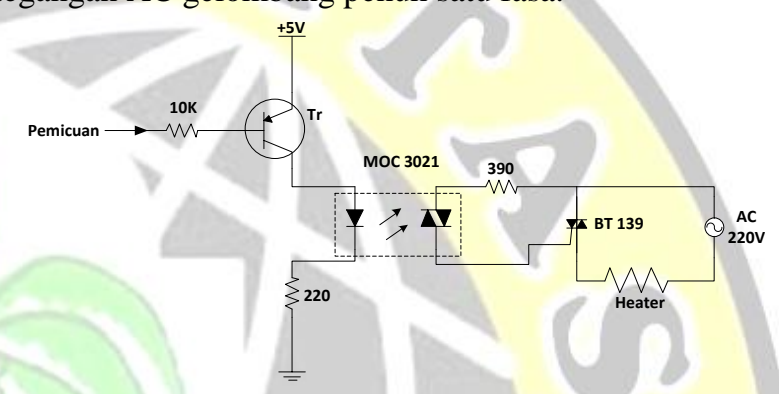

Gambar 2. Rangkaian konverter AC-AC

Zero crossing detector adalah rangkaian yang digunakan untuk mendeteksi gelombang sinus AC 220Volt saat melewati titik tegangan nol. Titik nol yang dideteksi adalah peralihan dari positif menuju negatif dan peralihan dari negatif menuju positif. Seberangan titik nol ini merupakan acuan yang digunakan sebagai awal pemberian nilai waktu tunda untuk pemicuan triac (Sudjadi, 2005).

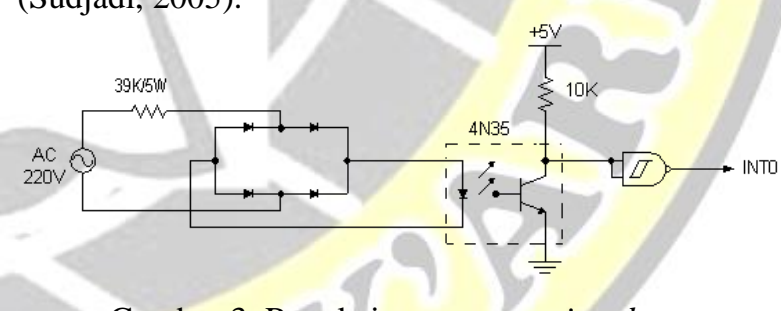

Gambar 3. Rangkaian zero crossing detector

\section{Sensor Suhu}

Sensor suhu yang dipakai pada penelitian ini adalah LM35. Sensor suhu LM35 adalah komponen elektronika yang memiliki fungsi untuk mengubah besaran suhu menjadi besaran listrik dalam bentuk tegangan. LM35 memiliki keakuratan tinggi dan kemudahan perancangan jika dibandingkan dengan sensor suhu yang lain, LM35 juga mempunyai keluaran impedansi yang rendah dan linieritas yang tinggi sehingga dapat dengan mudah dihubungkan dengan rangkaian kendali khusus serta tidak memerlukan penyetelan lanjutan.

LM35 yang dipakai pada alat ini, sudah dimodifikasi sedemikian rupa sehingga tahan air (water proof). Sensor 
ini memiliki output tegangan analog, sehingga kita perlu memasangkannya pada kaki ADC mikrokontroller. Resolusi ADC yang digunakan pada system ini menggunakan 10bit. Berdasarkan datasheet, tiap kenaikan 1 derajat, maka tegangan analog output $\operatorname{lm} 35$ akan naik sebesar $10 \mathrm{mV}$.

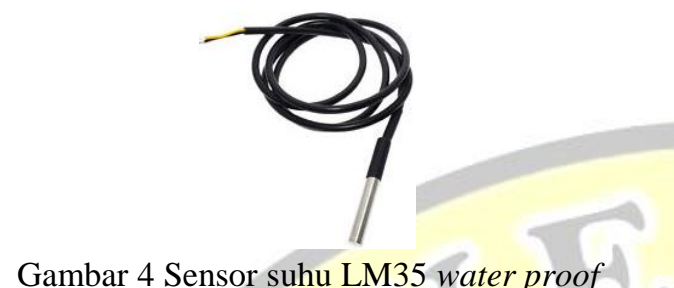

\section{Fuzzy logic control}

Dalam perancangan perangkat lunak fuzzy logic control dilakukan pada mikrokontroler atmega328. Desain kontrol digunakan untuk mengatur kerja sistem dengan tujuan utama melakukan proses pengaturan suhu berdasarkan fuzzy logic control untuk menghasilkan sinyal pemicuan bagi triac pada konverter AC-AC.

Struktur perancangan fungsi keanggotaan masukan untuk pemrograman pada mikrokontroler digunakan Error dan DError seperti yang ditunjukkan pada Gambar 5 dan Gambar 6. Fungsi keanggotaan masukan digunakan untuk proses fuzzifikasi yang akan memetakan nilai input Error dan DError sehingga diperoleh peubah fuzzy yang berupa derajat keanggotaan untuk setiap variabel linguistik Error dan Derror (Thiang, 1999).

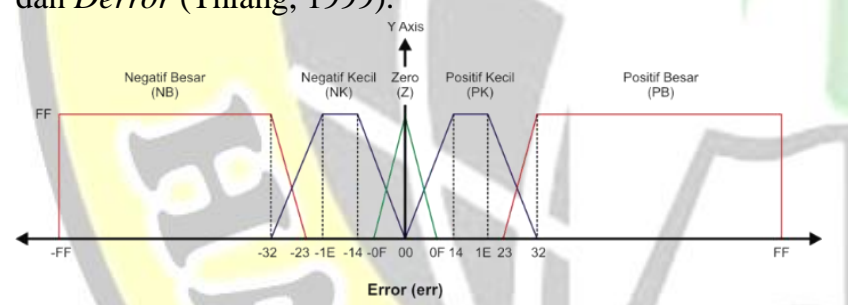

Gambar 5 Fungsi keanggotaan Error

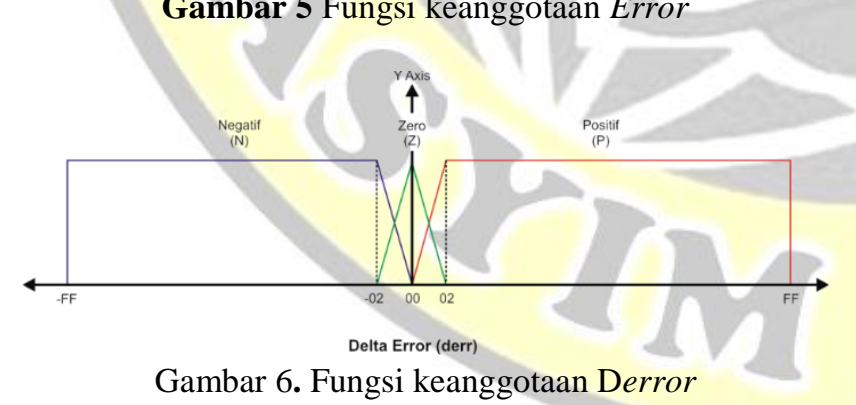

Dengan menggunakan aturan-aturan yang sudah dirancang di dalam basis aturan, sistem fuzzy logic control melakukan evaluasi terhadap input Error, DError dan menentukan fuzzy outputs berupa nilai grade untuk setiap variabel linguistik keluaran. Teknik yang digunakan untuk pengambilan keputusan sehingga didapatkan suatu penyelesaian dalam evaluasi aturan adalah metode MAX-
MIN. Rancangan basis aturan yang digunakan pada penelitian ini ditunjukkan Tabel 1.

Tabel 1 Rancangan basis aturan

\begin{tabular}{|c|c|c|c|c|c|c|}
\hline & \multicolumn{5}{|c|}{ Error } \\
\hline & & $\mathbf{B}_{(\boldsymbol{0})} \mathbf{N}$ & $\begin{array}{c}\mathbf{N} \\
\mathbf{K}_{(\mathbf{1})}\end{array}$ & (2) & $\begin{array}{c}\mathbf{P} \\
\mathbf{K}_{(3)}\end{array}$ & $\begin{array}{l}\mathbf{P} \\
\mathbf{B}_{(4)}\end{array}$ \\
\hline \multirow{3}{*}{ לे } & (0) & $\mathbf{S}_{(4)}{ }^{-B}$ & $\begin{array}{ll} & \text { BS } \\
\text { (4) } & \end{array}$ & $\begin{array}{ll} & \mathbf{B} \\
\text { (3) } & \end{array}$ & (1) & $\mathbf{S}_{(\boldsymbol{0})}{ }^{K}$ \\
\hline & (1) & $\mathbf{S}_{(4)}$ & $\begin{array}{ll} & \\
& \\
\text { (3) } & \\
\end{array}$ & $\begin{array}{ll} & \mathbf{S} \\
\text { (2) } & \\
\end{array}$ & $\begin{array}{ll} & \mathbf{K} \\
\text { (1) } & \\
\end{array}$ & $S_{(0)}^{K}$ \\
\hline & (2) & $S_{(4)}{ }^{B}$ & (3) & (1) $\begin{array}{r} \\
\end{array}$ & $\mathbf{S}_{(\boldsymbol{0})}{ }^{\mathbf{K}}$ & $\mathbf{S}_{(\mathbf{0})}{ }^{K}$ \\
\hline
\end{tabular}

Sebagai tahap akhir pada proses dasar pengendali logika fuzzy adalah proses defuzzifikasi. Pada proses defuzzifikasi dilakukan untuk mengkonversi setiap hasil dari basis aturan yang diekspresikan dalam bentuk fuzzy set kesuatu bilangan real. Metode yang digunakan untuk proses defuzzifikasi adalah Center of Gravity (COG).

Nilai keluaran merupakan parameter yang akan menentukan besarnya waktu tundaan pemicuan triac. Adapun fungsi keanggotaan yang digunakan untuk keluaran adalah fungsi keanggotaan yang berbentuk singleton. Rancangan fungsi keanggotaan keluaran ditunjukkan pada Gambar 7 dan pada Gambar 8 diperlihatkan bentuk hardware sistem yang telah dibuat.

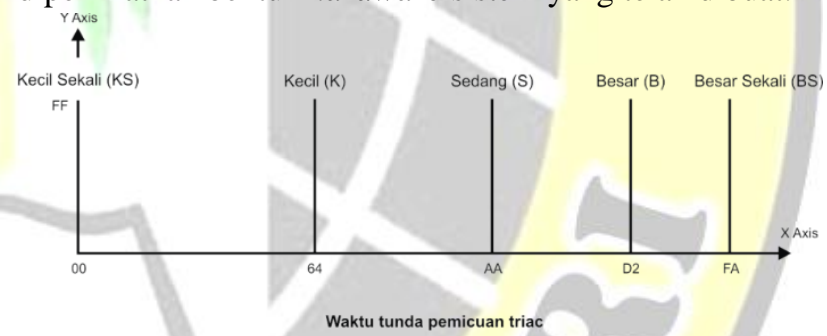

Gambar 7. Fungsi keanggotaan keluaran

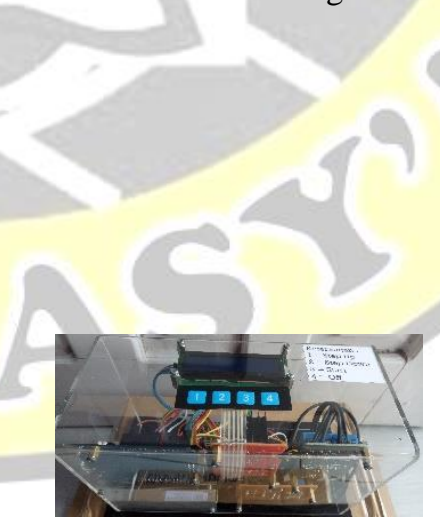

(a)

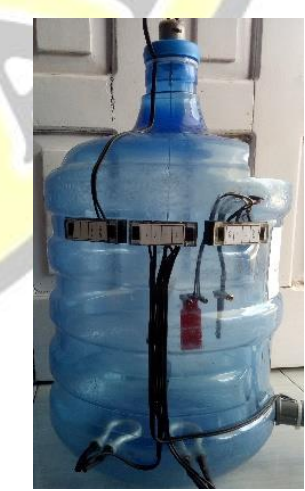

(b)
Gambar 8. Sistem pengaturan suhu, (a) Kontroler FLC dan (b) Tabung Reaksi

\section{HASIL DAN PEMBAHASAN}

Sebelum melakukan pembahasan akan dilakukan pengujian terlebih dahulu terhadap beberapa komponen 
dalam plant. Beberapa komponen yang akan diuji adalah kinerja sensor LM 35 Water Proof yang berperan sebagai komponen closed loop atau feedback. Komponen selanjutnya yang akan diuji adalah kinerja konverter AC$\mathrm{AC}$, apakah mampu menghasilkan tegangan yang berbeda sesuai dengan kebutuhan sistem dalam menghasilkan temperatur yang dibutuhkan. Pada dasarnya kontroler fuzzy logic control ini diterapkan agar mikrokontroler mampu mengatur sudut penyulutan konverter AC-AC.

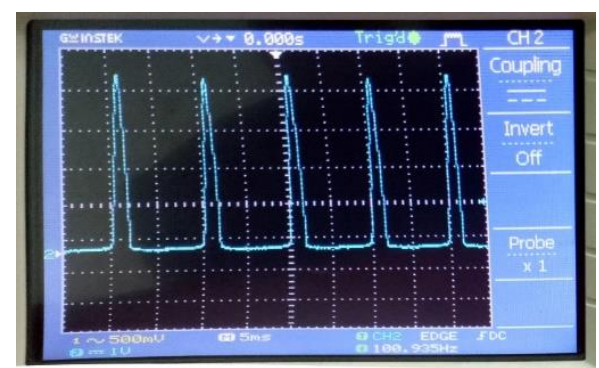

Gambar 9. Respon zero crossing detector

\section{Pengujian LM 35 Water Proof}

Pengujian ini ditujukan untuk membandingkan data yang ada pada sensor suhu LM35 dengan termometer analog, dimana termometer analog digunakan sebagai acuan atau referensi. Data yang diambil juga adalah hasil pembacaan pada ADC dengan resolusi 10bit.

Tabel 2 Respon sensor suhu LM35

\begin{tabular}{|c|c|c|}
\hline $\begin{array}{c}\text { Suhu Termometer } \\
\text { Analog }\left({ }^{\circ} \mathbf{C}\right)\end{array}$ & $\begin{array}{c}\text { Suhu LM35 } \\
\left({ }^{\mathbf{o}} \mathbf{C}\right)\end{array}$ & $\begin{array}{c}\text { Nilai ADC } \\
(\mathbf{D e c})\end{array}$ \\
\hline 30 & 30.3 & 66 \\
\hline 35 & 34.4 & 75 \\
\hline 40 & 39.5 & 86 \\
\hline 45 & 44.1 & 96 \\
\hline 50 & 49.1 & 107 \\
\hline 55 & 54.2 & 118 \\
\hline 60 & 59.2 & 129 \\
\hline 65 & 64.3 & 140 \\
\hline 70 & 69.3 & 151 \\
\hline 75 & 74.4 & 161 \\
\hline
\end{tabular}

Dari tabel respon sensor suhu LM35 dapat dilihat bahwa hasil pengukuran pada termometer analog dan LM35 tidak terdapat perbedaan yang berarti, sehingga kinerja sensor dapat disimpulkan cukup akurat. Temperatur pada LM35 hanya terpaut kurang dari $1{ }^{\circ} \mathrm{C}$ dari temperatur pada termometer analog.

\section{Pengujian konverter AC-AC}

Tujuan dari pengujian konverter AC-AC, untuk melihat kinerja zero crossing detector dan kinerja triac ketika diberi penyulutan pada sudut-sudut tertentu. Rangkaian zero crossing detector berfungsi untuk mendeteksi setiap gelombang sinus yang melewati titik nol, maka diperoleh frekuensi gelombang keluaran sebesar dua kali dari frekuensi gelombang sinus masukan. Adapun frekuensi gelombang sinus masukan adalah $50 \mathrm{~Hz}$, sehingga frekuensi gelombang keluaran adalah $2 \times 50=100$ $\mathrm{Hz}$.

Adapun gambar bentuk gelombang keluaran dari rangkaian zero crossing detector yang diuji dengan osciloscope dapat dilihat pada Gambar 9 di bawah ini :
Tabel 3 Respon konverter AC-AC

\begin{tabular}{|c|c|c|c|}
\hline $\boldsymbol{\alpha}\left({ }^{(}\right)$ & $\mathbf{V p}(\mathbf{V})$ & $\mathbf{V s}(\mathbf{V})$ & $\mathbf{I p}(\mathbf{A})$ \\
\hline 0 & 219,5 & 220.6 & 3.26 \\
\hline 20 & 217.9 & 220.6 & 3.26 \\
\hline 40 & 201.7 & 220.2 & 3.21 \\
\hline 60 & 177.8 & 220.7 & 3.06 \\
\hline 80 & 144.4 & 220.4 & 2.6 \\
\hline 100 & 107.7 & 220.2 & 2.34 \\
\hline 120 & 34.17 & 220.6 & 1.81 \\
\hline 140 & 22.67 & 220 & 1.16 \\
\hline 160 & 11.01 & 220.1 & 0.56 \\
\hline 180 & 0.63 & 220.4 & 0 \\
\hline
\end{tabular}

Dalam melakukan pengujian konverter AC-AC, diambil tegangan output dan arus output setelah dilakukan penyulutan pada sudut-sudut tertentu. Tabel 2 merupakan data yang didapat pada pengujian konverter AC-AC dengan variabel penyulutan 20 derajat.

Berdasarkan data diatas, tampak bahwa ketika sudut penyulutan $0^{\circ}$, tegangan output dari triac berkurang $1 \mathrm{~V}$ dari tegangan input. Hal ini dimungkinkan terjadi karena triac memiliki tahanan internal atau juga dikarenakan sudut penyulutan yang tidak benar-benar berada pada 0 , namun sedikit bergeser sehingga ada tegangan yang hilang. Namun rugi-rugi $1 \mathrm{~V}$ ini tidak terlalu merusak kinerja sistem dan sistem masih dapat dikatakan baik. Output konverter AC-AC yang terkontrol dapat dilihat pada gambar dibawah ini.

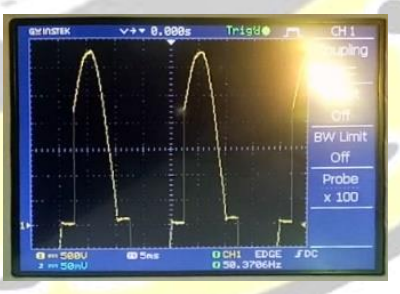

(a)

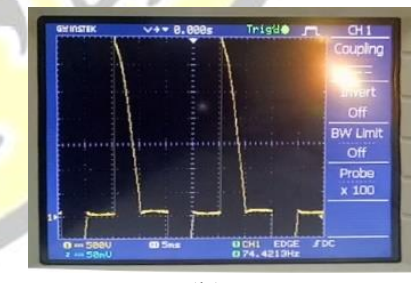

(b)

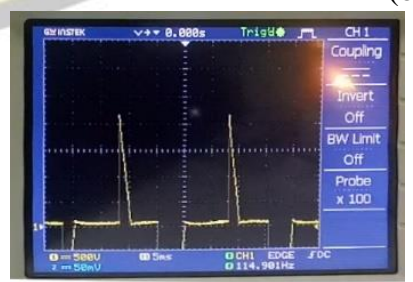

(c)

Gambar 10. Respon sudut penyulutan, (a) Sudut $135^{\circ}$, (b) Sudut $90^{\circ}$, dan (c) Sudut $45^{\circ}$ 


\section{Pengujian Fuzzy logic control}

Pengujian ini ditujukan untuk melihat respon suhu terhadap waktu setelah dilakukan pengontrolan menggunakan fuzzy logic control. Dengan adanya metode kontrol ini, diharapkan sistem akan cepat mencapai setpoint dan steady state. Sebagai pembanding antara sistem terkontrol menggunakan fuzzy logic control dan sistem yang tak terkontrol, maka diambil data untuk sistem tak terkontrol (open loop).

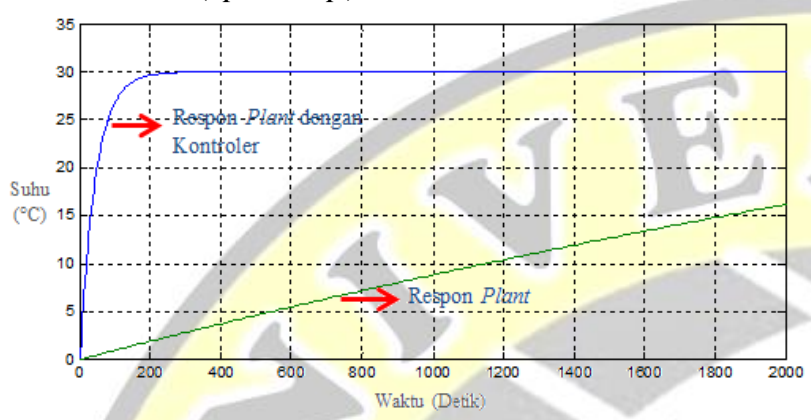

Gambar 11. Respon pengaturan suhu dengan FLC dan tanpa FLC

Berdasarkan grafik diatas, tampak bahwa suhu mencapai suhu $15^{\circ} \mathrm{C}$ (setengah nilai setpoint) dalam waktu 30 menit. Tentu hal ini terlalu lama dan memakan waktu serta biaya. Hal ini benar-benar tidak efisien dan merugikan banyak pihak. Oleh karena keterbatasan tersebut maka diterapakan kontroler fuzzy logic control. Hasil dari penerapan kontroler tersebut, time respond mengalami percepatan sangat signifikan seperti terlihat pada Gambar 11.

Dengan menerapkan fuzzy logic control waktu yang dibutuhkan dapat kurang dari 5 menit agar sistem dapat mencapai posisi steady state. Ketika sistem telah mencapai steady state, sudut penyulutan cenderung berada pada kisaran $126^{\circ}$, jika diperhatikan di osciloscope, maka berikut adalah gambar dari sinyal ketika telah steady state.

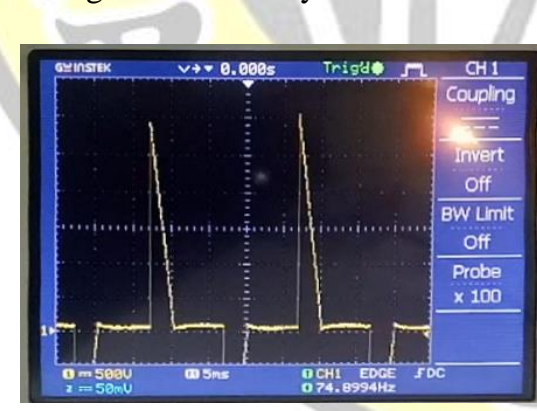

Gambar 12. Respon konverter AC-AC saat plant pada posisi steady state

\section{PENUTUP}

Setelah melakukan tahap perancangan dan pembuatan sistem yang kemudian dilanjutkan dengan tahap pengujian dan analisa maka dapat diambil kesimpulan bahwa sistem pengatur suhu ini dapat bekerja dengan baik. Hal ini dibuktikan dengan respon suhu yang konstan pada setpoint $30^{\circ} \mathrm{C}$. Fuzzy logic control pada sistem ini menghasilkan
Rise time sebesar 3 menit, serta ketika telah mencapai setpoint suhu $30^{\circ} \mathrm{C}$, suhu sedikit berosilasi dengan error steady state $0 \%$.

\section{DAFTAR PUSTAKA}

Kitcharoenwat, S., Konghirun, M., \& Sangswang, A. (2013). A Novel Single Phase AC-AC Converter with Power Factor Control. ECTI TRANSACTIONS ON ELECTRICAL ENG., ELECTRONICS, AND COMMUNICATIONS , 26-31.

Maidah, N. E., Putra, A. E., \& Pulungan, M. R. (2012). Perancangan Perangkat Keras Pengendali Fuzzy erbasis Mikrokontroler ATmega32 sebagai Pengendali Suhu dan Kelembaban. The 1st Symposium in Industrial Technology (pp. C42-C50). Yogyakarta: UPNVY.

Puspita, E. S., \& Yulianti, L. (2016). Perancangan Sistem Peramalan Cuaca Berbasis Logika fuzzy. Jurnal Media Infotama, 1-10.

Sudjadi, \& Sakti, E. P. (2005). Pengaturan Cahaya Lampu Sebagai Fotosintesis Phytoplankton Buatan Dengan Mengunakan Mikrokontroler AT89S52. Transmisi, 11-14.

Thiang, Hannawati, A., Eng, B., \& Resmana. (1999). Sistem Pengembangan kendali Fuzzy Logic Berbasis Mikrokontroler Keluarga MCS51 (PetraFuz). JURNAL INFORMATIKA, 1-10. 